\title{
Fibrinogen/Lymphocyte Count Ratio Can Be Used as a New Indicator of Prognosis in Patients with Hepatocellular Carcinoma After Radical Resection
}

This article was published in the following Dove Press journal: Cancer Management and Research

\author{
Yicheng $\mathrm{Li}^{\mathrm{I}-3, *}$ \\ Zhengli $\mathrm{Li}^{2}, *$ \\ Kangjian Deng ${ }^{2, *}$ \\ Minjun Liao ${ }^{2,4}$ \\ Shengguang Yuan ${ }^{1,2}$ \\ Zhaoquan Huang ${ }^{2,5}$ \\ 'Department of Hepatobiliary and \\ Pancreatic Surgery, The Second Affiliated \\ Hospital of Guilin Medical University, \\ Guilin 54I199, Guangxi, People's \\ Republic of China; ${ }^{2}$ Laboratory of \\ Hepatobiliary and Pancreatic Surgery, \\ Affiliated Hospital of Guilin Medical \\ University, Guilin 54I00I, Guangxi, \\ People's Republic of China; ${ }^{3}$ Second \\ Clinical Medical College, Guangxi Medical \\ University, Nanning 53002I, Guangxi, \\ People's Republic of China; ${ }^{4}$ Science \\ Experiment Center, Guangxi Medical \\ University, Nanning, Guangxi, 53002I, \\ People's Republic of China; ${ }^{5}$ Department \\ of Pathology, Guilin Medical University, \\ Guilin 541001, Guangxi, People's \\ Republic of China
}

*These authors contributed equally to this work
Correspondence: Zhaoquan Huang; Shengguang Yuan Laboratory of Hepatobiliary and Pancreatic Surgery, Affiliated Hospital of Guilin Medical University, Guilin 54100I, Guangxi, People's Republic of China Email 477922581@qq.com; yuanshengguang6@163.com
Purpose: Preoperative fibrinogen levels are associated with the development, recurrence and metastasis of malignant tumors. This study was designed to investigate the clinical value of preoperative fibrinogen/lymphocyte count ratio (FLR) index in hepatocellular carcinoma (HCC).

Patients and Methods: The clinical data of 479 patients with HCC who underwent radical resection were retrospectively analyzed. The correlation between FLR and clinicopathological features was analyzed by chi-square test or non-parametric test. The overall survival (OS) and progression-free survival (PFS) were analyzed by Kaplan-Meier method.

Results: The optimal cut-off value of FLR was determined as 1.6 according to the receiver operating characteristic curve (ROC) analysis, in order to predict prognosis for HCC patients after radical resection. It was further found that FLR level was correlated with tumor size, TNM stage, microvascular invasion and prognosis. Multivariate Cox regression analyses found that FLR was an independent predictor for postoperative OS (overall survival) ( $p=$ $0.002)$ and PFS (progression-free survival) $(p=0.001)$ in patients with HCC; and the 1-, 3and 5-year OS and PFS of HCC patients in the FLR $\leq 1.6$ level group were significantly higher than those in the FLR $>1.6$ level group.

Conclusion: Preoperative FLR level is a novel and effective predictor of prognosis in patients with HCC, and elevated FLR level is associated with poor prognosis in patients with HCC.

Keywords: hepatocellular carcinoma, FLR, prognosis, recurrence

\section{Introduction}

Hepatocellular carcinoma (HCC), one of the leading causes of cancer death in China, is insidious and has a high degree of malignancy. ${ }^{1}$ Radical resection and professional rehabilitation training can improve the overall survival of patients with $\mathrm{HCC}^{2}{ }^{2}$ however, HCC patients' long-term survival is still poor, ${ }^{3}$ and some biomarkers were reported and used to predict the prognosis of HCC patients and guide clinical decision-making. At present, the conventional and classic factors indicators used to predict the prognosis of HCC are AFP, tumor size, TNM stage, microvascular invasion, etc. In view of the existence of obvious heterogeneity of HCC, it is necessary to explore more novel potential factors for sub-stratification analyses. Therefore, it is important to find more effective biomarkers to identify high-risk patients who are prone to suffer from recurrence and metastasis and provide better personalized treatments. 
The inflammatory response plays an important role in the progression of malignant tumors. ${ }^{4}$ Inflammatory cells such as neutrophils, ${ }^{5}$ macrophages, ${ }^{6}$ and lymphocytes ${ }^{7}$ are all involved in the biological behaviors of tumors. Fibrinogen is a coagulation factor synthesized in hepatic cells, is one kind of the positive acute-phase proteins, and fibrinogen is often increased during systemic inflammation. ${ }^{8}$ On one hand, as a hemostatic factor, fibrinogen is a key factor in tumor progression; on the other hand, fibrinogen can bind to receptors that regulate tumor progression by regulating cell proliferation, cell migration, and apoptosis, ${ }^{9}$ and therefore, affect tumor progression. Recent studies have shown that inflammatory response-related biomarkers can potentially predict the prognosis of tumors, such as systemic immune-inflammation index (SII), ${ }^{10}$ neutrophil to lymphocyte ratio (NLR), ${ }^{11,12}$ platelet lymphocyte ratio (PLR),${ }^{13}$ lymphocyteto-monocyte ratio (LMR), ${ }^{14,15}$ etc. As a new and effective method to predict the prognosis of cancer patients, inflammation index will be much more concerned. In view of the important role of fibrinogen and lymphocytes in tumor progression, this study focused on the potential application value of plasma fibrinogen level to peripheral blood lymphocyte ratio (FLR) index in the prognosis of HCC.

\section{Patients and Methods}

\section{Research Object}

The clinical data of $479 \mathrm{HCC}$ patients who underwent radical resection in our hospital from 2006 to 2012 were retrospectively studied. The inclusion criteria were: postoperative pathological diagnosis of HCC; received radical resection and without distant metastasis. The exclusion criteria were: did not receive surgery, did not receive radical surgery, received liver transplantation, received anti-tumor therapy such as radiotherapy or chemotherapy before surgery; radiographic examination confirmed recurrence within 2 months after surgery; death within 2 months after surgery. And 156 patients were excluded due to the lack of clinical data, and therefore a total of 479 patients were enrolled and analyzed in this study. This study is in line with the declaration of Helsinki Principles. This study was approved by the Ethics Committee of the Affiliated Hospital of Guilin Medical University, and complied with the Declaration of Helsinki. Written informed consent was obtained from all patients (Figure 1).

\section{Clinical Information}

Patients' general information and clinical data were collected, including gender, age, and laboratory results.
Patients with liver cancer $(n=1496)$

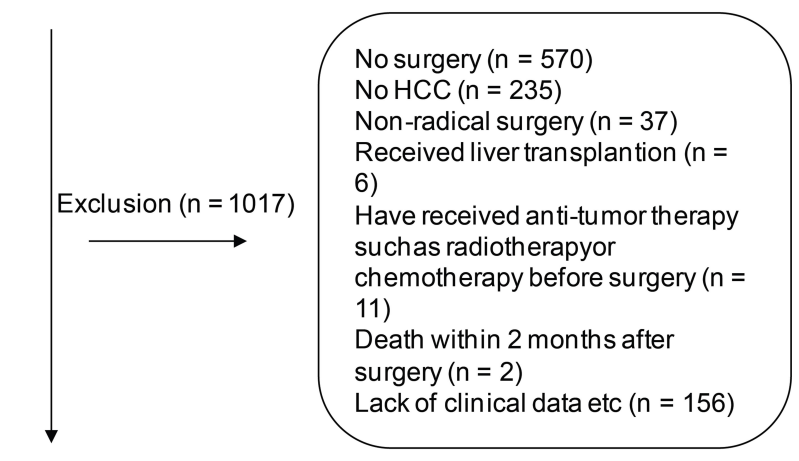

479 patients were included in the final analysis

Figure I Flow chart shows the selection of patients eligible for this study.

Laboratory tests include blood routines and biochemical indicators. Tumor size, tumor number, tumor location, and microvascular invasion were determined according to the postoperative specimens. The clinical stage of the tumor refers to the TNM staging criteria (Table 1).

\section{Follow-Up and Observation Index}

All patients were followed up regularly by outpatient service or telephone until death or the deadline of March 31, 2019. The patients were reviewed every 2 months within the first 2 years after surgery and every 3-6 months thereafter. The follow-up monitoring includes symptoms, signs, blood routine, blood biochemistry, liver function, serum alpha-fetoprotein (AFP), abdominal ultrasonography, etc., and Computed Tomography (CT) or Magnetic Resonance Imaging (MRI) examinations if necessary. Progression free survival (PFS) was defined as the time from surgery to recurrence, metastasis, death or the last follow-up, and overall survival (OS) was defined as the time from surgery to death or the last follow-up.

\section{Statistical Analysis}

Part of the data was expressed as the mean $\pm \mathrm{SD}$, and statistical analyses were performed using the SPSS22.0 software (SPSS Inc., Chicago, IL). $p<0.05$ was considered statistically significant. The correlation between FLR and clinicopathological characteristics was analyzed by chi-square test or non-parametric test. OS and PFS were analyzed by Kaplan-Meier method using the Log rank 
Table I Clinical and Biochemical Data of Examined Patients

\begin{tabular}{|c|c|}
\hline Parameter & Mean $\pm S D *$ \\
\hline Age (years) & $50.21 \pm 11.46$ \\
\hline HBsAg: positive/negative (n) & $402 / 77$ \\
\hline Tumor size (range, $\mathrm{cm}$ ) & $8.31 \pm 4.92$ \\
\hline WBC $\left(\times 10^{9} / \mathrm{L}\right)$ & $6.40 \pm 2.31$ \\
\hline LYMPH (×109/L) & $1.65 \pm 0.6 \mathrm{I}$ \\
\hline Platelets $\left(\times 10^{9} / \mathrm{L}\right)$ & $183.65 \pm 79.86$ \\
\hline Albumin $(g / L)$ & $38.59 \pm 4.78$ \\
\hline Globulin (g/L) & $31.07 \pm 6.05$ \\
\hline TB $(\mu \mathrm{mol} / \mathrm{L}):$ median, range & $13.37(3.66-229.05)$ \\
\hline $\mathrm{DB}(\mu \mathrm{mol} / \mathrm{L}):$ median, range & $4.9(0.5-168.2)$ \\
\hline ALT $(U / L)$ & $47.28 \pm 45.6 \mathrm{I}$ \\
\hline AST (U/L) & $54.07 \pm 48.26$ \\
\hline ALP $(U / L)$ & $102.72 \pm 68.15$ \\
\hline AFP & $337.2(0.25-328,030)$ \\
\hline FIB & $2.96 \pm 1.05$ \\
\hline FLR & $2.05 \pm 1.14$ \\
\hline
\end{tabular}

Note: *Data presented as mean \pm SD or others.

Abbreviations: $\mathrm{SD}$, standard deviation; $\mathrm{N}$, number of patients; $\mathrm{HBs} A$ g, hepatitis $\mathrm{B}$ surface antigen; AFP, alpha-fetoprotein; WBC, white blood cell; LYMPH, lymphocyte count; TB, total bilirubin; DB, direct bilirubin; ALT, alanine aminotransferase; AST, aspartate aminotransferase; ALP, alkaline phosphatase.

test. Cox regression model was used to evaluate the multifactor hazard ratio.

\section{Results}

\section{The Optimal Cutoff Value of FLR}

The ROC curve analysis was used to obtain the optimal cut-off value of FLR, and the optimal cut-off value was determined as 1.6 to predict postoperative patients' survival, with relatively high sensitivity and specificity (Figure 2).

\section{Relationship Between Preoperative FLR Level and Clinicopathological Characteristics of HCC}

The relationship between preoperative FLR and clinicopathological variables in patients with HCC was analyzed, as is shown in Table 2. The optimal cut-off value of FLR was determined according to the ROC curve and then all patients were divided into two groups: low FLR level group (FLR $\leq 1.6, \mathrm{n}=196$ ) and high FLR level group $(\mathrm{FLR}>1.6, \mathrm{n}=283)$. The results showed that there was a positive correlation between FLR level and tumor size ( $>5$ cm) $\left(\chi^{2}=32.69, p<0.001\right)$, TNM III-IV stage $\left(\chi^{2}=\right.$ 33.86, $p<0.001)$, microvascular invasion $\left(\chi^{2}=19.40, p\right.$ $<0.001)$ and recurrence $\left(\chi^{2}=9.218, p=0.002\right)$. However, no correlation was found between preoperative FLR and

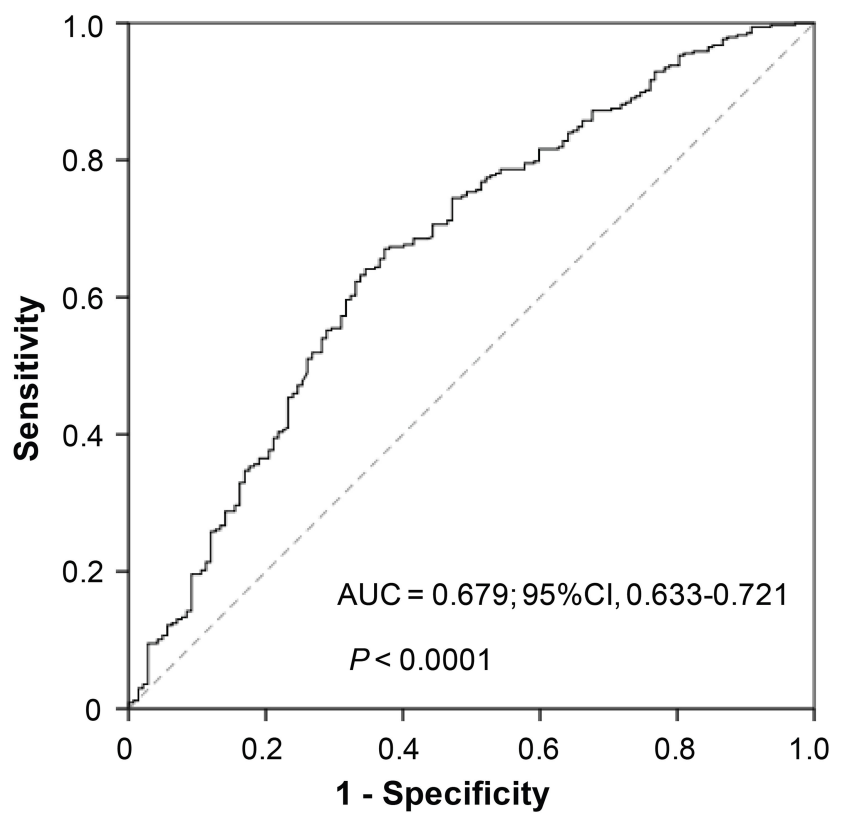

Figure 2 Determination of the cut-off value for FLR in HCC patients. Abbreviations: FLR, plasma fibrinogen level to lymphocyte ratio; HCC, hepatocellular carcinoma.

age, hepatitis B surface antigen, tumor number, alcohol consumption, and serum alpha-fetoprotein level $(p>0.05)$. Figure $3 \mathrm{~A}-\mathrm{C}$ showed that TNM stage, tumor size, and microvascular invasion were positively correlated with FLR levels $(p<0.001)$. The above results suggested that high FLR level status was more likely to promote malignant progression, invasion and postoperative recurrence of HCC.

\section{Predictive Factors Analysis of OS and PFS for Postoperative HCC Patients}

Univariate analysis showed that preoperative FLR $>1.6$ $(\mathrm{HR}=2.03 ; 95 \% \mathrm{CI}: 1.62-2.51, p<0.001)$, tumor size $(>5$ $\mathrm{cm}$ ), tumor number $\geq 2$, TNM III-IV stage, recurrence, microvascular invasion, AFP $>20 \mathrm{ng} / \mathrm{mL}$ were unfavorable predictors of OS. Multivariate Cox regression model analysis suggested that preoperative FLR $>1.6(\mathrm{HR}=1.56$; 95\% CI: $1.18-2.09, p=0.002)$, tumor size $(>5 \mathrm{~cm})$, TNM III-IV stage, recurrence, microvascular invasion were independent predictors of shorter OS. Likewise, in the univariate analysis, preoperative FLR $>1.6(\mathrm{HR}=1.96$; 95\% CI: $1.60-2.47, p<0.001$ ), tumor size ( $>5 \mathrm{~cm}$ ), tumor number $\geq 2$, TNM III-IV stage, microvascular invasion, AFP $>20 \mathrm{ng} / \mathrm{mL}$ were unfavorable predictors of PFS. And multivariate Cox regression model analysis revealed that only preoperative FLR $>1.6(\mathrm{HR}=1.58 ; 95 \% \mathrm{CI}$ : $1.21-2.10, p=0.001)$, tumor size $(>5 \mathrm{~cm})$, TNM III-IV 
Table 2 Correlation Between the Clinicopathologic Variables and FLR in HCC

\begin{tabular}{|c|c|c|c|c|c|c|}
\hline \multirow[t]{2}{*}{ Clinical Character } & \multirow[t]{2}{*}{ Clinical Variable } & \multirow[t]{2}{*}{ No.of Patients } & \multicolumn{2}{|l|}{ FLR level } & \multirow[t]{2}{*}{$x^{2}$} & \multirow[t]{2}{*}{$p$ value } \\
\hline & & & $\leq 1.6 \mathrm{n}(\%)$ & $>1.6 \mathrm{n}(\%)$ & & \\
\hline Age (years) & $\begin{array}{l}\leq 55 \\
>55\end{array}$ & $\begin{array}{l}319 \\
160\end{array}$ & $\begin{array}{l}|3|(4|.|) \\
65(40.6)\end{array}$ & $\begin{array}{l}188(58.9) \\
95(59.4)\end{array}$ & 0.009 & 0.926 \\
\hline $\mathrm{HBsAg}$ & $\begin{array}{l}\text { Negative } \\
\text { Positive }\end{array}$ & $\begin{array}{l}77 \\
402\end{array}$ & $\begin{array}{l}34(44.2) \\
162(40.3)\end{array}$ & $\begin{array}{l}43(55.8) \\
240(59.7)\end{array}$ & 0.398 & 0.528 \\
\hline Tumor size (range, $\mathrm{cm}$ ) & $\begin{array}{l}\leq 5 \\
>5\end{array}$ & $\begin{array}{l}170 \\
309\end{array}$ & $\begin{array}{l}99(58.2) \\
97(31.4)\end{array}$ & $\begin{array}{l}7 I(4 I .8) \\
2 I 2(68.6)\end{array}$ & 32.69 & $<0.001$ \\
\hline Tumor number & $\begin{array}{l}\text { Single } \\
\text { Multiple }\end{array}$ & $\begin{array}{l}351 \\
128\end{array}$ & $\begin{array}{l}146(41.6) \\
50(39.1)\end{array}$ & $\begin{array}{l}205(58.4) \\
78(60.9)\end{array}$ & 0.249 & 0.618 \\
\hline Drinking & $\begin{array}{l}\text { Absent } \\
\text { Present }\end{array}$ & $\begin{array}{l}267 \\
212\end{array}$ & $\begin{array}{l}\mathrm{II} 4(42.7) \\
82(38.7)\end{array}$ & $\begin{array}{l}153(57.3) \\
130(61.3)\end{array}$ & 0.789 & 0.374 \\
\hline TNM stage & $\begin{array}{l}\text { I-II } \\
\text { III-IV }\end{array}$ & $\begin{array}{l}210 \\
269\end{array}$ & $\begin{array}{l}\mathrm{II} 7(55.7) \\
79(29.4)\end{array}$ & $\begin{array}{l}93(44.3) \\
190(70.6)\end{array}$ & 33.86 & $<0.001$ \\
\hline Microvascular invasion & $\begin{array}{l}\text { Absent } \\
\text { Present }\end{array}$ & $\begin{array}{l}34 \mid \\
138\end{array}$ & $\begin{array}{l}|6|(47.2) \\
35(25.4)\end{array}$ & $\begin{array}{l}180(52.8) \\
103(74.6)\end{array}$ & 19.40 & $<0.001$ \\
\hline Recurrence & $\begin{array}{l}\text { Absent } \\
\text { Present }\end{array}$ & $\begin{array}{l}367 \\
112\end{array}$ & $\begin{array}{l}164(44.7) \\
32(28.6)\end{array}$ & $\begin{array}{l}203(55.3) \\
80(71.4)\end{array}$ & 9.218 & 0.002 \\
\hline $\operatorname{AFP}(\mathrm{ng} / \mathrm{mL})$ & $\begin{array}{l}\leq 20 \\
>20\end{array}$ & $\begin{array}{l}143 \\
336\end{array}$ & $\begin{array}{l}67(46.9) \\
129(38.4)\end{array}$ & $\begin{array}{l}76(53.1) \\
207(6 I .6)\end{array}$ & 2.970 & 0.85 \\
\hline
\end{tabular}

Abbreviations: FLR, plasma fibrinogen level to lymphocyte ratio; N, number of patients; HBsAg, hepatitis B surface antigen; TNM, tumor-node-metastasis; AFP, alphafetoprotein; AST, aspartate aminotransferase.

stage, microvascular invasion were independent predictors of shorter PFS (Table 3).

\section{The Predictive Value of FLR and the Novel Model Based on 4 Variables for OS and PFS in HCC}

According to the Kaplan-Meier analysis, in the low FLR level group, the median OS was 69.2 months and the median PFS was 60.4 months, whereas in the high FLR level group, the median OS was 44.2 months and the median PFS was 34.4 months. As for PFS, the 1-, 3-, and 5-year progression-free survival rates of patients in the low FLR level group were significantly higher than those in the high FLR level group, respectively ( $74 \%$ vs $56.25 \%, 46.5 \%$ vs $43.6 \%$ and $24.1 \%$ vs $18.9 \%, p<0.001)$. For OS, the 1-, 3-, and 5-year overall survival rates of the low FLR level group were significantly higher than those of the high FLR level group $(86.7 \%$ vs $77.4 \%, 61.7 \%$ vs $39.6 \%$ and $48.8 \%$ vs $25.4 \%, p<0.001$ ) (Figure $4 \mathrm{~A}$ and $\mathrm{B}$ ).

Then, each of the four important variables was assigned and re-evaluated in order to construct a new scoring model, including FLR, tumor size, TNM stage, and microvascular invasion. One point would be given to the following circumstances: FLR $>1.6$, tumor size $(>5$ $\mathrm{cm}$ ), TNM III-IV stage, and microvascular invasion; otherwise, the score is 0 . Therefore, the highest score is 4 , and the lowest score is 0 . According to their scores, HCC patients were divided into the low-risk group (score 0 points), the medium-risk group (score 1-2), and the high-risk group (score 3-4). The analysis revealed that PFS $\left(p<0.001, \chi^{2}=81.8\right)$ and OS $\left(p<0.001, \chi^{2}=\right.$ 111.2) were significantly different among the three groups (Figure 4C and D), suggesting that this novel scoring model constructed by four variables may have favorable predictive value for the prognosis of HCC.

\section{Comparison of FLR and AFP on PFS and OS in Subgroups of HCC}

In the subgroup of patients with tumor size $\leq 3 \mathrm{~cm}$, compared to FLR $\leq 1.6$, patients with FLR $>1.6$ had a shorter PFS (median survival time: 82.2 vs 50.8 months, $p=$ 0.011 ), and a shorter OS (median survival time: 88.0 vs 60.9 months, $p=0.023$ ) (Figure 5A-D); similar results 

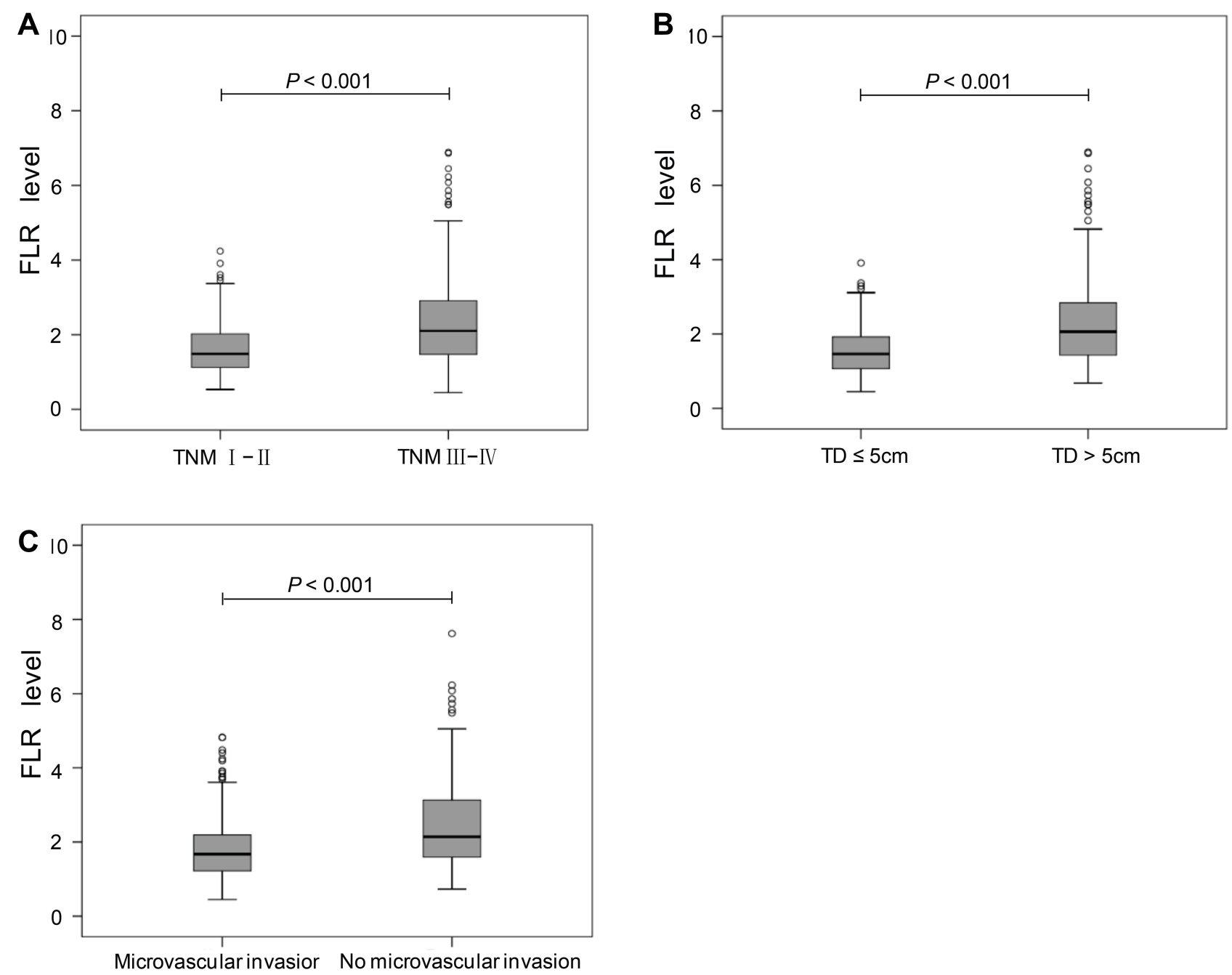

Figure 3 Box plot showing the relationship between FLR levels and TNM stage (A) TD (B) and Microvascular invasion (C). Abbreviations: TD, tumor diameter; TNM, tumor-node-metastasis.

were found in the subgroup of patients with tumor size $\leq 5$ $\mathrm{cm}$ : patients with FLR $>1.6$ had a shorter PFS (median survival time: 77.1 vs 48.4 months, $p<0.001$ ) and a shorter OS (median survival time: 85.8 vs 60.8 months, $p$ $<0.001$ ) (Figure 5E-H). In contrast, there was no prognostic prediction value for AFP (cut-off value: $20 \mathrm{ng} / \mathrm{mL}$ ) in the above two subgroups.

\section{Discussion}

Researches on the mechanism of tumor progression and improvements on tumor treatment strategies will help improve the quality of life for HCC patients. ${ }^{16}$ The mechanism of hepatoma's development and progression is complicated; and it is the result of a combination of various factors, and one critical factor is the inflammation condition. Inflammation is closely related to the occurrence of tumors. ${ }^{4}$ Inflammation in the tumor microenvironment also promotes tumor growth, proliferation and metastasis. Chronic hepatitis is also a major factor in the development of HCC, and inflammation in the liver micro-environment can promote the development of liver cancer. ${ }^{17}$ Fibrinogen, a coagulation factor synthesized in hepatocytes, is one kind of the positive acute-phase proteins that plays an important role in the development of inflammation. Fibrinogen can change the functions of inflammatory cells function through different receptors and mechanisms. ${ }^{18}$ As a hemostatic factor, fibrinogen is the critical and decisive factor of tumor cell's metastasis potency, for it can combine with other proteins and deposit on the extracellular matrix, and then functioning as a scaffold, which can combine with the growth factors, as a result, promotes cell proliferation, adhesion and tumor metastasis. ${ }^{19}$ Studies have shown that elevated serum fibrinogen levels are associated with poor prognosis in patients 
Table 3 Univariate and Multivariate Cox Regression Analyses of the FLR with Clinicopathologic Characteristics

\begin{tabular}{|c|c|c|c|c|c|c|}
\hline \multirow[t]{2}{*}{ Variables } & \multicolumn{3}{|c|}{ Univariate Analysis } & \multicolumn{3}{|c|}{ Multivariate Analysis } \\
\hline & HR & $95 \% \mathrm{Cl}$ & $p$ value & HR & $95 \% \mathrm{Cl}$ & $p$ value \\
\hline \multicolumn{7}{|l|}{ Overall survival } \\
\hline FLR (> I.6 vs $\leq 1.6)$ & 2.03 & $|.62-2.5|$ & $<0.001$ & 1.56 & I.18-2.09 & 0.002 \\
\hline Gender (male vs female) & I.II & $0.80-1.53$ & 0.526 & & & \\
\hline Age, yeas (> 55 vs $\leq 55)$ & 0.85 & $0.68-1.07$ & 0.163 & & & \\
\hline HBsAg (positive vs negative) & 1.01 & $0.75-1.34$ & 0.960 & & & \\
\hline Cirrhosis (positive vs negative) & 0.97 & $0.66-1.40$ & 0.884 & & & \\
\hline Tumor size, $\mathrm{cm}(>5$ vs $\leq 5)$ & 2.30 & $1.76-2.87$ & $<0.001$ & 1.39 & $1.09-1.76$ & 0.007 \\
\hline Tumor number (multiple vs single) & 1.42 & $1.12-1.80$ & 0.003 & & & \\
\hline Drinking (present vs absent) & 1.06 & $0.86-|.3|$ & 0.572 & & & \\
\hline TNM stage (III-IV vs I-II) & 2.37 & $2.02-3.12$ & $<0.001$ & 1.71 & $1.31-2.26$ & $<0.001$ \\
\hline Recurrence (present vs absent) & 2.06 & $1.70-2.65$ & $<0.001$ & 1.62 & $1.26-2.16$ & 0.001 \\
\hline Vascular invasion (present vs absent) & 2.16 & $1.76-2.63$ & $<0.001$ & $1.4 \mathrm{I}$ & $1.09-1.84$ & 0.009 \\
\hline AFP, ng/mL (> 20 vs $\leq 20)$ & 1.45 & $1.16-1.86$ & 0.002 & & & \\
\hline \multicolumn{7}{|l|}{ Progression-free survival } \\
\hline $\operatorname{FLR}(>1.6$ vs $\leq 1.6)$ & 1.96 & $1.60-2.47$ & $<0.001$ & 1.58 & $1.21-2.10$ & 0.001 \\
\hline Gender (male vs female) & 1.07 & $0.77-1.48$ & 0.656 & & & \\
\hline Age, yeas (> 55 vs $\leq 55$ ) & 0.89 & $0.7 I-1.12$ & 0.329 & & & \\
\hline HBsAg (positive vs negative) & 1.02 & $0.76-1.36$ & 0.905 & & & \\
\hline Cirrhosis (positive vs negative) & 0.98 & $0.67-1.4 \mid$ & 0.953 & & & \\
\hline Tumor size, $\mathrm{cm}(>5$ vs $\leq 5)$ & 2.12 & $1.68-2.66$ & $<0.001$ & 1.38 & $1.08-1.75$ & 0.008 \\
\hline Tumor number (multiple vs single) & 1.38 & $1.09-1.72$ & 0.007 & & & \\
\hline Drinking (present vs absent) & 1.04 & $0.84-1.29$ & 0.700 & & & \\
\hline TNM stage (III-IV vs I-II) & 2.24 & $1.86-2.83$ & $<0.001$ & 1.66 & $\mid .32-2.31$ & $<0.001$ \\
\hline Vascular invasion (present vs absent) & 1.89 & $1.53-2.32$ & $<0.001$ & 1.43 & $1 .|2-1.8|$ & 0.004 \\
\hline AFP, ng/mL (> 20 vs $\leq 20)$ & 1.44 & $1.13-1.82$ & 0.004 & & & \\
\hline
\end{tabular}

Abbreviations: $\mathrm{HR}$, hazard ratio; $\mathrm{Cl}$, confidence interval; $\mathrm{HBsAg}$, hepatitis $\mathrm{B}$ surface antigen; TNM, tumor-node-metastasis; AFP, alpha-fetoprotein.

with liver cancer, ${ }^{20-22}$ esophageal cancer, ${ }^{23}$ ovarian cancer. ${ }^{24}$ The involvement of lymphocytes in the immune function plays an extremely important role in many aspects, such as tumor immunization assessment ${ }^{25}$ and immunological therapy. ${ }^{26}$

In this study, the optimal cut-off value of FLR was determined to be 1.6 , and based on this value, elevated FLR level was found to be positively correlated with tumor size, TNM stage, microvascular invasion, recurrence, and poor prognosis of HCC, suggesting that FLR may play a crucial role in HCC, and that high FLR level can promote tumor's growth, vascular invasion and other biological behaviors evolution in HCC, and then exert a great impact on the recurrence and survival prognosis of postoperative $\mathrm{HCC}$ patients. In view of this important finding, the malignant progression of $\mathrm{HCC}$ could be postponed, postoperative recurrence could be reduced and patients' survival time may be prolonged, if HCC patients' physical condition is well managed, such as the fibrinogen level and inflammatory condition are well controlled, the immune environment is improved, etc.

For patients with elevated FLR and poor prognosis, it is possible to select appropriate treatment methods based on the actual clinical conditions of the patients, such as consider the combined treatment of transarterial chemoembolization (TACE) + radiofrequency ablation (RFA) instead of surgical resection. ${ }^{27}$ Furthermore, the application of different staging standards also has an impact on the prognosis of HCC patients. ${ }^{28}$ The current international staging standards include Barcelona Clinic Liver Cancer (BCLC) staging system, Hong Kong Liver Cancer (HKLC) staging system, TNM staging system, etc. Medical institutions should select a more suitable staging system for their HCC patients. ${ }^{29}$

Except for FLR being an independent predictor of survival prognosis in HCC, some previous studies have 
found that larger tumor size (greater than $5 \mathrm{~cm}$ ), higher TNM stage (stage III-IV), and microvascular invasion are all independent predictors for poor prognosis of HCC. In this study, these results have been verified again. Interestingly, the new scoring model precisely consisting of the above four independent predictive factors has prominent prognostic potency for $\mathrm{HCC}$, and its potential significance is worthy of further discussions.

Although the study has found a series of indicators or models that appear to be useful in the diagnosis and prognosis of HCC, AFP is still the index for HCC's diagnosis and postoperative monitoring in clinical practice, but

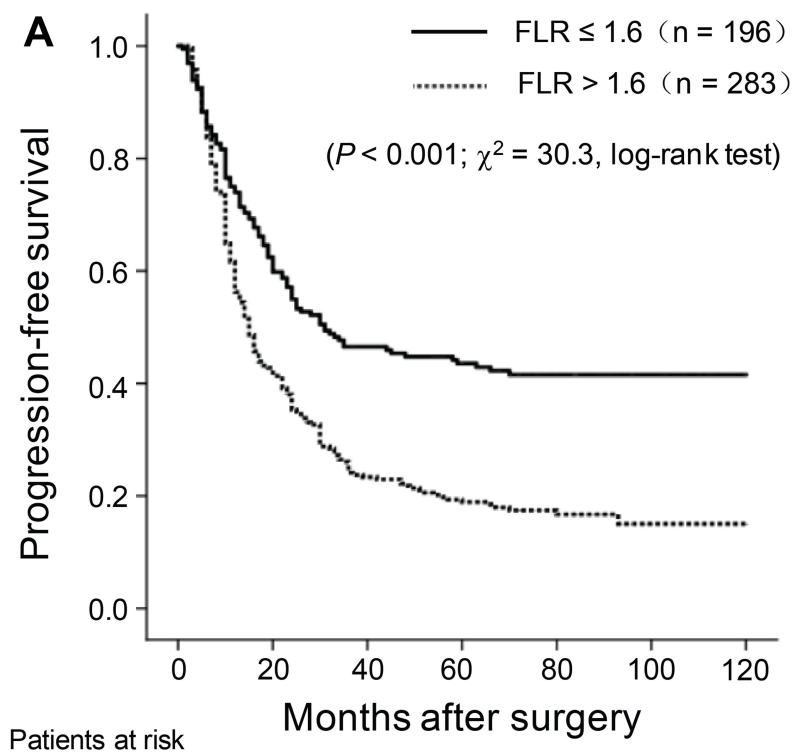

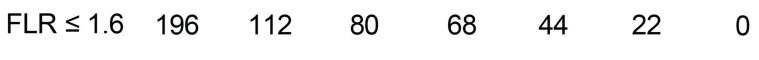

$\begin{array}{llllllll}\text { FLR }>1.6 & 283 & 113 & 60 & 42 & 21 & 4 & 0\end{array}$

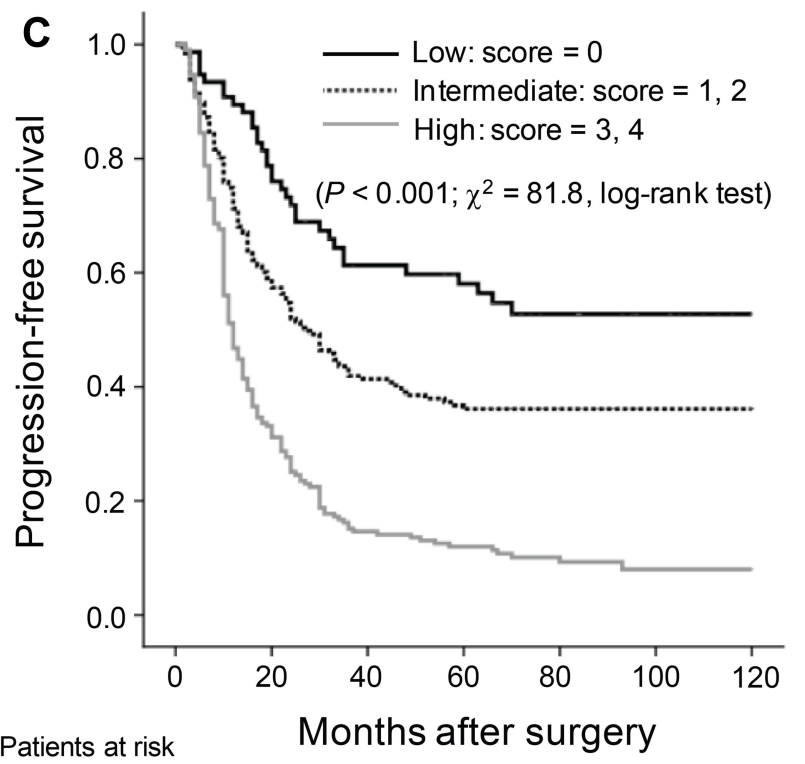

$\begin{array}{lccccccc}\text { Low } & 76 & 55 & 39 & 35 & 21 & 9 & 0 \\ \text { Intermediate } & 196 & 107 & 73 & 55 & 33 & 13 & 0 \\ \text { High } & 207 & 63 & 28 & 20 & 11 & 4 & 0\end{array}$

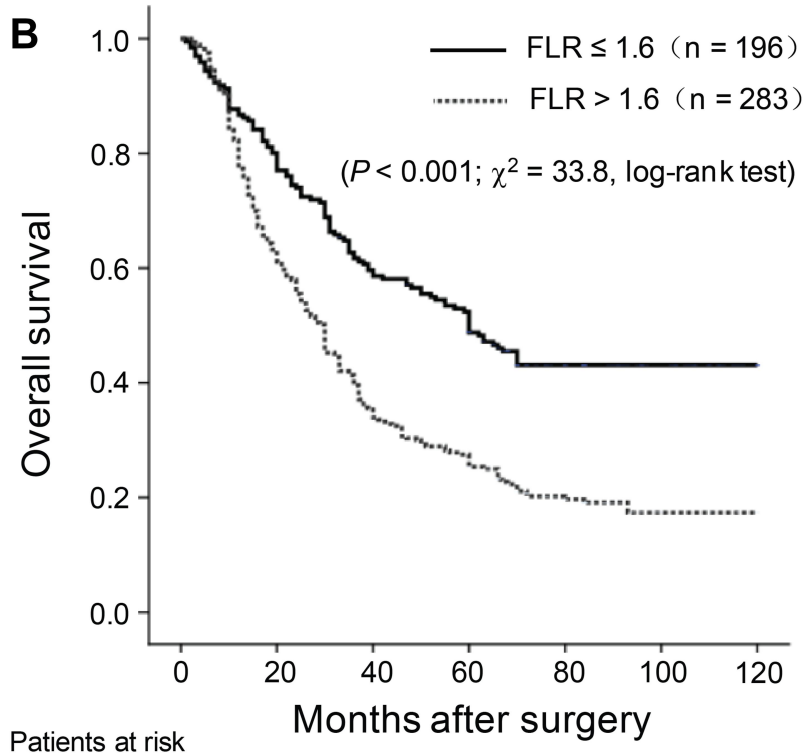

\begin{tabular}{|c|c|c|c|c|c|}
\hline FLR $\leq 1.6$ & 196 & 151 & 114 & 90 & 53 \\
\hline
\end{tabular}

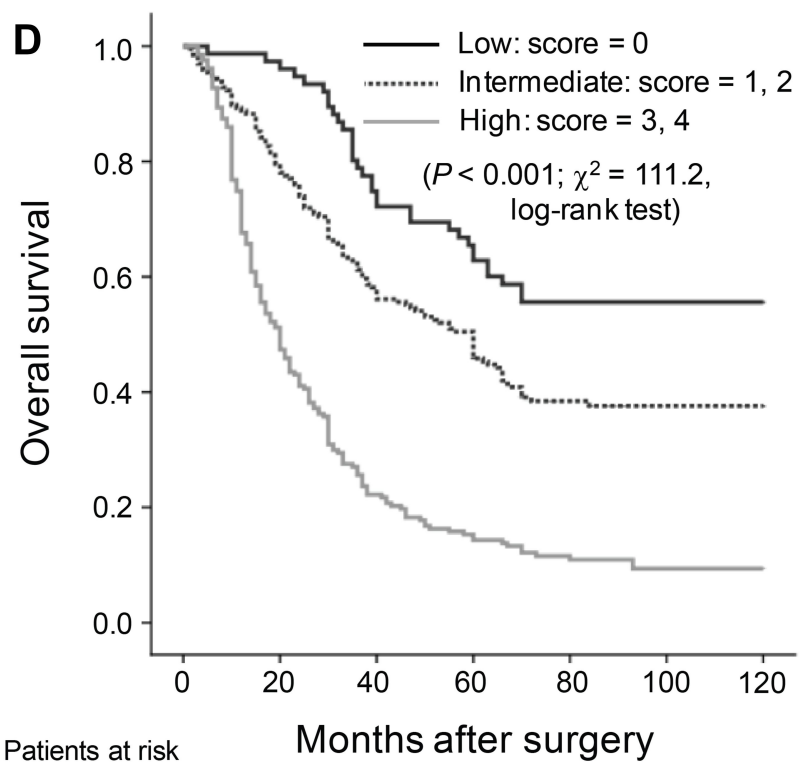

$\begin{array}{lccccccc}\text { Low } & 76 & 73 & 54 & 46 & 26 & 11 & 0 \\ \text { Intermediate } & 196 & 153 & 110 & 85 & 45 & 15 & 0 \\ \text { High } & 207 & 98 & 45 & 28 & 16 & 4 & 0\end{array}$

Figure 4 Kaplan-Meier curves of progression-free survival (A) and overall survival (B) are shown for HCC patients. Progression-free survival curves (C) and overall survival curves (D) for the HCC patients according to the score. 

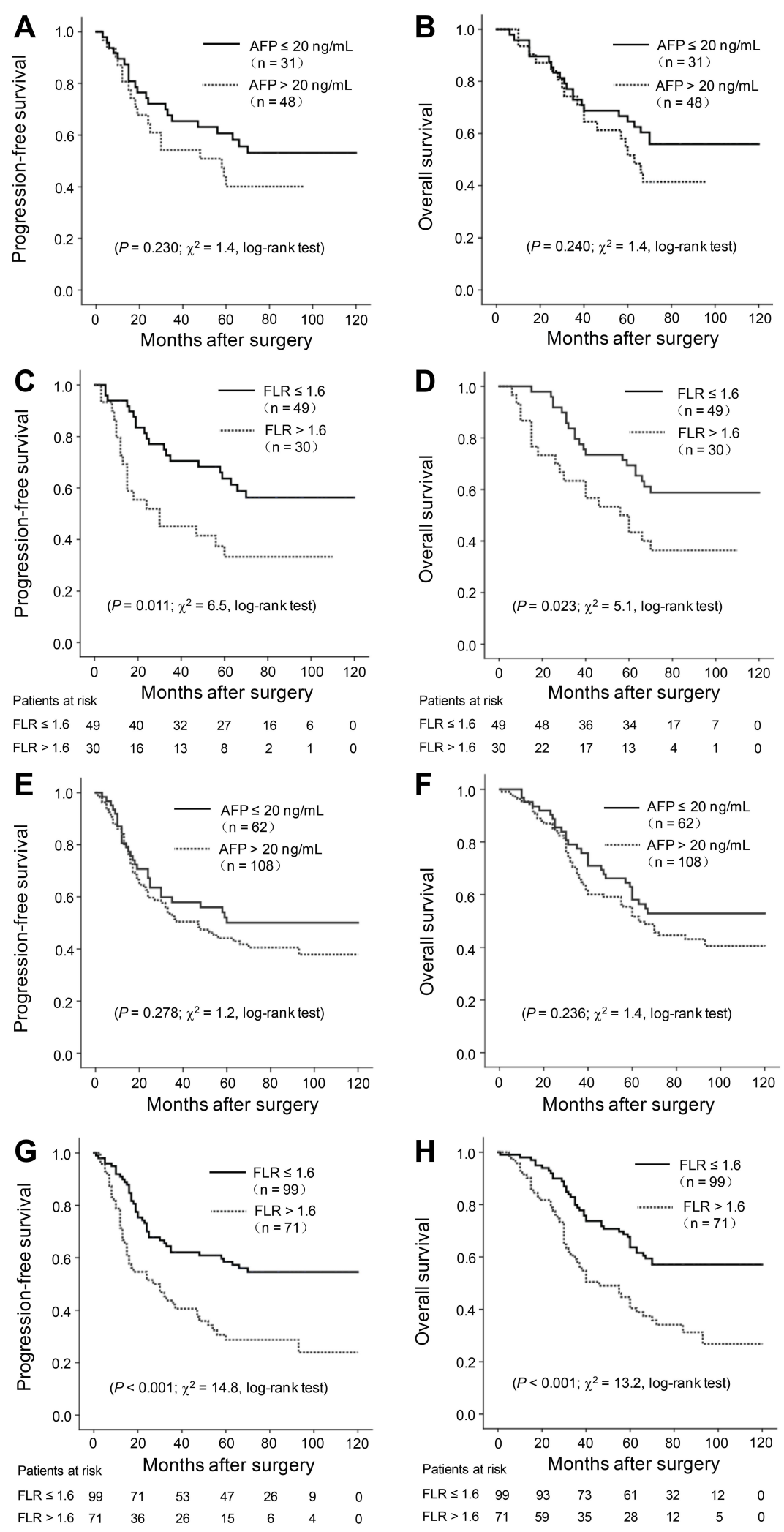

Figure 5 Kaplan-Meier analysis revealed the relationship of FLR and AFP with PFS or OS in the HCC patients with tumor size $<3 \mathrm{~cm}(\mathbf{A}-\mathbf{D})$ and tumor size $<5 \mathrm{~cm}(\mathbf{E}-\mathbf{H})$. 
actually, AFP's ability to predict prognosis for small and medium-sized HCC is limited. ${ }^{30}$ In this study, we investigated the postoperative survival of HCC patients with tumor size $\leq 5 \mathrm{~cm}$ and $\leq 3 \mathrm{~cm}$, respectively, and the results showed that AFP has no prognostic significance in these sub-groups; in contrast, HCC patients in these sub-groups can be favorably divided into two significant groups: FLR $\leq 1.6$ group and FLR $>1.6$ group. It was suggested that FLR may be a new potential indicator of HCC's prognosis prediction, and FLR may be better than AFP to some extent.

This study also has certain limitations. For example, this was a retrospective study in which patients were selected from a single medical institution with $83.9 \%$ cases were hepatitis B-related HCC, 156 patients were excluded due to lack of clinical data, and the data of FLR were collected preoperatively. In the following studies, multi-centered and different viral types originated HCC patients should be enrolled in prospective analyses, and regular follow-up data should also be added for comprehensive demonstration of FLR's potential value in the prognosis of HCC. The FLR, a low-cost and easily obtained indicator for HCC prognosis, is worthy of further investigations for its important significance in the future clinical practice; and it is expected that FLR might have greater potential for more accurate prognostic prediction and better guidance significance for clinical decision-making in HCC patients.

\section{Acknowledgments}

This work was supported in part by the National Natural Science Foundation of China (No. 81773148), the National Key Sci-Tech Special Project of China (No. 2018ZX10302207) and the Natural Science Foundation of Guangxi (No. 2018GXNSFDA138001).

\section{Disclosure}

The authors report no conflicts of interest in this work.

\section{References}

1. Chen W, Zheng R, Baade PD, et al. Cancer statistics in China, 2015. CA Cancer J Clin. 2016;66(2):115-132. doi:10.3322/caac.21338

2. Wang B, Shelat VG, Chow JJL, et al. Prehabilitation program improves outcomes of patients undergoing elective liver resection. $J$ Surg Res. 2020;251:119-125. doi:10.1016/j.jss.2020.01.009

3. Gluer AM, Cocco N, Laurence JM, et al. Systematic review of actual 10 -year survival following resection for hepatocellular carcinoma. Hpb. 2012;14(5):285-290. doi:10.1111/j.1477-2574.2012.00446.x

4. Grivennikov SI, Greten FR, Karin M. Immunity, inflammation, and cancer. Cell. 2010;140(6):883-899. doi:10.1016/j.cell.2010.01.025
5. Coffelt SB, Kersten K, Doornebal CW, et al. IL-17-producing gammadelta $\mathrm{T}$ cells and neutrophils conspire to promote breast cancer metastasis. Nature. 2015;522(7556):345-348. doi:10.1038/nature14 282

6. Na YR, Je S, Seok SH. Metabolic features of macrophages in inflammatory diseases and cancer. Cancer Lett. 2018;413:46-58. doi:10.10 16/j.canlet.2017.10.044

7. Ostroumov D, Fekete-Drimusz N, Saborowski M, et al. CD4 and CD8 T lymphocyte interplay in controlling tumor growth. Cell Mol Life Sci. 2018;75(4):689-713. doi:10.1007/s00018-017-2686-7

8. Ghanim B, Hoda MA, Klikovits T, et al. Circulating fibrinogen is a prognostic and predictive biomarker in malignant pleural mesothelioma. Br J Cancer. 2014;110(4):984-990. doi:10.1038/bjc.2013.815

9. Steinbrecher KA, Horowitz NA, Blevins EA, et al. Colitis-associated cancer is dependent on the interplay between the hemostatic and inflammatory systems and supported by integrin alpha(M)beta(2) engagement of fibrinogen. Cancer Res. 2010;70(7):2634-2643. doi:10.1158/0008-5472.CAN-09-3465

10. Hu B, Yang XR, Xu Y, et al. Systemic immune-inflammation index predicts prognosis of patients after curative resection for hepatocellular carcinoma. Clin Cancer Res. 2014;20(23):6212-6222. doi:10. 1158/1078-0432.CCR-14-0442

11. Shelat VG. Role of inflammatory indices in management of hepatocellular carcinoma-neutrophil to lymphocyte ratio. Ann Transl Med. 2020;8(15):912. doi:10.21037/atm-2020-90

12. Robinson AV, Keeble C, Lo MCI, et al. The neutrophil-lymphocyte ratio and locoregional melanoma: a multicentre cohort study. Cancer Immunol Immun. 2020;69(4):559-568. doi:10.1007/s00262-019-024 78-7

13. Kabir T, Ye M, Mohd Noor NA, et al. Preoperative neutrophil-tolymphocyte ratio plus platelet-to-lymphocyte ratio predicts the outcomes after curative resection for hepatocellular carcinoma. Int $J$ Hepatol. 2019;2019:4239463. doi:10.1155/2019/4239463

14. Nishijima TF, Muss HB, Shachar SS, et al. Prognostic value of lymphocyte-to-monocyte ratio in patients with solid tumors: a systematic review and meta-analysis. Cancer Treat Rev. 2015;41 (10):971-978. doi:10.1016/j.ctrv.2015.10.003

15. Mandaliya H, Jones M, Oldmeadow C, et al. Prognostic biomarkers in stage IV non-small cell lung cancer (NSCLC): neutrophil to lymphocyte ratio (NLR), lymphocyte to monocyte ratio (LMR), platelet to lymphocyte ratio (PLR) and advanced lung cancer inflammation index (ALI). Transl Lung Cancer Res. 2019;8(6):886-894. doi:10.21037/tlcr.2019.11.16

16. Ahmed S, de Souza NN, Qiao W, et al. Quality of life in hepatocellular carcinoma patients treated with transarterial chemoembolization. HPB Surg. 2016;2016:6120143. doi:10.1155/2016/6120143

17. Galun E. Liver inflammation and cancer: the role of tissue microenvironment in generating the tumor-promoting niche (TPN) in the development of hepatocellular carcinoma. Hepatology. 2016;63 (2):354-356. doi:10.1002/hep.28344

18. Luyendyk JP, Schoenecker JG, Flick MJ. The multifaceted role of fibrinogen in tissue injury and inflammation. Blood. 2019;133 (6):511-520. doi:10.1182/blood-2018-07-818211

19. Palumbo JS, Kombrinck KW, Drew AF, et al. Fibrinogen is an important determinant of the metastatic potential of circulating tumor cells. Blood. 2000;96(10):3302-3309. doi:10.1182/blood.V96.10.3302

20. Simpson-Haidaris PJ, Rybarczyk B. Tumors and fibrinogen. The role of fibrinogen as an extracellular matrix protein. Ann N Y Acad Sci. 2001;936:406-425. doi:10.1111/j.1749-6632.2001.tb03525.x

21. Huang G, Jiang H, Lin Y, et al. Prognostic value of plasma fibrinogen in hepatocellular carcinoma: a meta-analysis. Cancer Manag Res. 2018;10:5027-5041. doi:10.2147/CMAR.S175780

22. Gan W, Yi Y, Fu Y, et al. Fibrinogen and C-reactive protein score is a prognostic index for patients with hepatocellular carcinoma undergoing curative resection: a prognostic nomogram study. $J$ Cancer. 2018;9(1):148-156. doi:10.7150/jca.22246 
23. Zhang X, Long Q. Elevated serum plasma fibrinogen is associated with advanced tumor stage and poor survival in hepatocellular carcinoma patients. Medicine (Baltimore). 2017;96(17):e6694. doi:10.10 97/MD.0000000000006694

24. Lv GY, Yu Y, An L, et al. Preoperative plasma fibrinogen is associated with poor prognosis in esophageal carcinoma: a meta-analysis. Clin Transl Oncol. 2018;20(7):853-861. doi:10.1007/s12094-0171794-Z

25. Luo Y, Kim HS, Kim M, et al. Elevated plasma fibrinogen levels and prognosis of epithelial ovarian cancer: a cohort study and meta-analysis. J Gynecol Oncol. 2017;28(3):e36. doi:10.3802/jgo.2017.28.e36

26. Dieci MV, Radosevic-Robin N, Fineberg S, et al. Update on tumorinfiltrating lymphocytes (TILs) in breast cancer, including recommendations to assess TILs in residual disease after neoadjuvant therapy and in carcinoma in situ: a report of the International Immuno-Oncology Biomarker Working Group on Breast Cancer. Semin. Cancer Biol. 2018;52:16-25. doi:10.1016/j.semcancer.2017.10.003
27. Zhang D, He W, Wu C, et al. Scoring system for tumor-infiltrating lymphocytes and its prognostic value for gastric cancer. Front Immunol. 2019;10:71. doi:10.3389/fimmu.2019.00071

28. Gui CH, Baey S, D'Cruz RT, et al. Trans-arterial chemoembolization + radiofrequency ablation versus surgical resection in hepatocellular carcinoma - A meta-analysis. Eur J Surg Oncol. 2020;46(5):763771. doi:10.1016/j.ejso.2020.01.004

29. Selby LKE, Tay RXY, Woon WWL, et al. Validity of the Barcelona clinic liver cancer and Hong Kong liver cancer staging systems for hepatocellular carcinoma in Singapore. J Hepatobiliary Pancreat Sci. 2017;24(3):143-152. doi:10.1002/jhbp.423

30. Giannini EG, Marenco S, Borgonovo G, et al. Alpha-fetoprotein has no prognostic role in small hepatocellular carcinoma identified during surveillance in compensated cirrhosis. Hepatology. 2012;56(4):13711379. doi:10.1002/hep. 25814

\section{Publish your work in this journal}

Cancer Management and Research is an international, peer-reviewed open access journal focusing on cancer research and the optimal use of preventative and integrated treatment interventions to achieve improved outcomes, enhanced survival and quality of life for the cancer patient.
The manuscript management system is completely online and includes a very quick and fair peer-review system, which is all easy to use. Visit http://www.dovepress.com/testimonials.php to read real quotes from published authors. 